\title{
ECP Handbook: Introducing and Mainstreaming the Provision of Emergency Contraceptive Pills in Developing Countries
}

\author{
Sharif M.I. Hossain \\ Population Council \\ M.E. Khan \\ Population Council \\ Ricardo Vernon \\ Jill Keesbury \\ Population Council \\ Ian Askew \\ Population Council
}

See next page for additional authors

Follow this and additional works at: https://knowledgecommons.popcouncil.org/departments_sbsr-rh

Part of the Demography, Population, and Ecology Commons, Family, Life Course, and Society Commons, Gender and Sexuality Commons, International Public Health Commons, Medicine and Health Commons, and the Women's Health Commons

How does access to this work benefit you? Let us know!

\section{Recommended Citation}

Hossain, Sharif M.I., M.E. Khan, Ricardo Vernon, Jill Keesbury, lan Askew, John Townsend, and Victoria Rumbold. 2009. "ECP Handbook: Introducing and Mainstreaming the Provision of Emergency Contraceptive Pills in Developing Countries." Washington, DC: Population Council. 


\section{Authors}

Sharif M.I. Hossain, M.E. Khan, Ricardo Vernon, Jill Keesbury, Ian Askew, John Townsend, and Victoria Rumbold 
Introducing and Mainstreaming the Provision of Emergency Contraceptive Pills in Developing Countries 

Introducing and Mainstreaming the Provision of Emergency Contraceptive Pills in Developing Countries

\author{
Sharif M. I. Hossain \\ M.E. Khan \\ Ricardo Vernon \\ Jill Keesbury \\ Ian Askew \\ John Townsend \\ Victoria Rumbold
}


The information contained in this handbook reflects inputs from several persons in addition to the authors. Much of the information about EC programming in Africa and in Latin America and the Caribbean is drawn from reviews of the literature undertaken by Jacinta Muteshi and Araceli Fernandez respectively. The final draft of the handbook was reviewed by Patricia Stephenson (USAID), Nicole Gray (William and Flora Hewlett Foundation), Elizabeth Westley (International Consortium for Emergency Contraception), and Francine Coeytaux (Compton Foundation).

The authors and the Population Council would like to acknowledge the financial support from USAID and the William and Flora Hewlett Foundation in producing this handbook and for their commitment to mainstreaming ECPs in Africa and Asia, and to the Compton and Concept Foundations for their vision and support to ECafrique.

THE WILLIAM AND FLORA H E W L E T T

F O U N D T I O N
This handbook was made possible by the generous support of the American people through the United States Agency for International Development (USAID) under Cooperative Agreement Number HRN A-00-98-00012-00 and by the William and Flora Hewlett Foundation under Project Number 2007-1124. The contents are the responsibility of the Population Council and do not necessarily reflect the views of USAID, the United States Government, or the William and Flora Hewlett Foundation. 1 Population Council

Published: March 2009

4301 Connecticut Avenue, Suite 280, Washington, DC www.popcouncil.org

Suggested citation: Hossain, Sharif M.I. et al. 2009. "ECP handbook: Introducing and mainstreaming the provision of emergency contraceptive pills in developing countries," FRONTIERS Manual. Washington, DC: Population Council.

(c) 2009 The Population Council, Inc.

The Population Council reserves all rights of ownership of this document. No part of this publication may be reproduced, stored or transmitted in any form by any means electronic, photocopying, recording or otherwise without the permission of the Population Council. 
For many women, emergency contraceptive pills (ECPs) offer an opportunity to prevent unintended pregnancy following contraceptive method failure, rape or unprotected sex. Access to this safe, effective option remains an essential element of women's quality reproductive healthcare. However, ECPs remain inaccessible across much of the world, as both supply and demand constraints undermine potential clients' ability to effectively use the method. This is particularly true in developing countries, where limited commodity supplies, provider competency, public awareness, and misinformation routinely coalesce to restrict the availability of ECPs. While ECPs have been introduced on a pilot basis in many countries, their effective integration into both the public and private sectors has lagged in the face of competing priorities. Successful interventions are guided by the principle that provision of ECPs is not exclusively the responsibility of government family planning programs, and so seek to mainstream delivery of ECPs by developing linkages with private sector providers and pharmacies, the HIV/AIDS sector, and sexual assault services.

As with the introduction of most contraceptive methods that are new to a national program, the process of successfully introducing ECPs into a country's health care system is a complex and usually protracted undertaking. This handbook is designed to provide step-by-step guidance for introducing and mainstreaming ECPs within a variety of country contexts, in a manner that will be responsive to their diverse needs and resource availability.

Production of this handbook was a collaborative effort between two projects of the Population Council's Reproductive Health Program: the Frontiers in Reproductive Health (FRONTIERS) project, funded by USAID; and the ECafrique network, funded by the William and Flora Hewlett Foundation. It synthesizes systematically documented programming practices drawn from a range of experiences in Africa, Asia, and Latin America and the Caribbean over the past decade. The handbook has been compiled from four unpublished reviews conducted by FRONTIERS (Muteshi and Keesbury 2007; Fernández and Vernon 2007; Khan and Hossain 2007; Fernández et al. 2008) and from selected documents that provide complementary guidance specific to the delivery of ECPs after their introduction and mainstreaming (e.g. PATH 2004; Pathfinder 2007).

The intended audience for this handbook includes reproductive health (RH) program managers and government and NGO policy makers. It can be used in countries where ECPs are not currently available, as well as in contexts where the intention is to expand or mainstream access to existing ECP services. The handbook:
$\checkmark$ recognizes the different needs of diverse segments of the population, and places additional emphasis on targeting ECP services to "special groups," which include rape survivors and adolescents.
$\checkmark$ seeks to present an overall process that can be adapted to specific contexts and that is based on documented successful experiences in a range of contexts.
$\checkmark$ guides policymakers and program managers through the continuum of ECP programming: from needs assessments and operations research, to registration, to training, logistics, and ultimately mainstreaming through nationwide scaling-up.

The handbook contains four sections:

Introduction and Background describes the existing situation of ECP programming around the globe.

Addressing the Needs of Specific Populations describes programming approaches designed for specific populations.

Introducing and Mainstreaming ECPs describes five chronological steps for making ECP programming an integral component of a national RH program.

The Bibliography lists useful resources for ECP programming. 
Introduction and Background .............................................................................................. 1

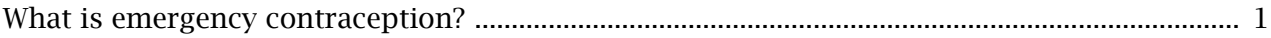

Why are ECPs important? ...................................................................................................... 1

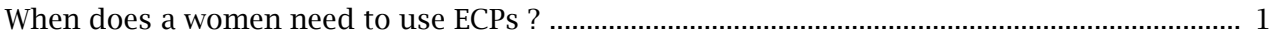

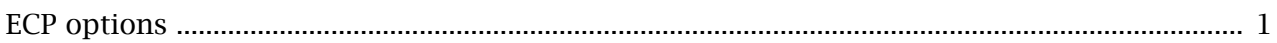

Efficacy and side effects .................................................................................................. 1

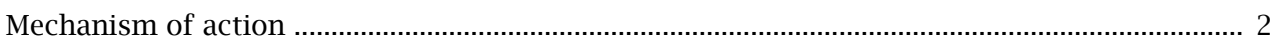

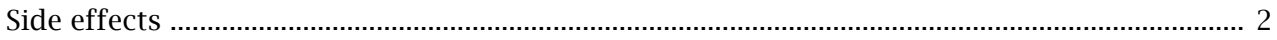

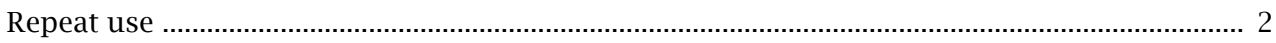

ECPs and STIs, including HIV ................................................................................................. 2

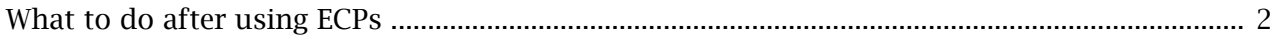

The bridging role of ECPs ..................................................................................................... 3

Provision of ECPs in different settings ……............................................................................ 3

Addressing the Needs of Specific Populations ...................................................................... 5

Identification of populations with specific needs ...................................................................... 5

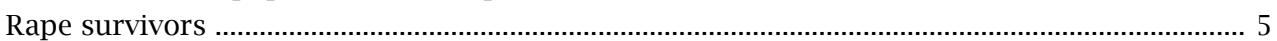

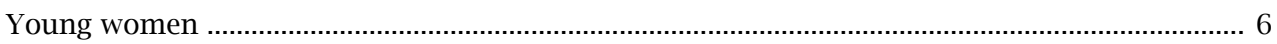

Women living in humanitarian settings .................................................................................. 7

Introducing and Mainstreaming ECPs ................................................................................... 9

Step 1. Registration of a dedicated ECP product ...................................................................... 9

Step 2. Introduction of ECPs into the public sector and NGOs ................................................. 10

Step 3. Training and building the capacity of ECP providers ....................................................... 13

Step 4. Making the case for and raising public awareness of ECPs ............................................. 16

Step 5. Mainstreaming: Scale up and sustainable institutionalization of ECP services ............... 19

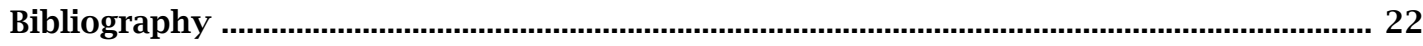




\begin{tabular}{|c|c|}
\hline AIDS & Acquired Immuno-Deficiency Syndrome \\
\hline ART & Anti-Retroviral Therapy \\
\hline ARV & Anti-Retrovirals \\
\hline CBD & Community-Based Distributor \\
\hline $\mathrm{COC}$ & Combined Oral Contraceptive \\
\hline CTU & Contraceptive Technology Update \\
\hline DHS & Demographic and Health Survey \\
\hline EC & Emergency Contraception \\
\hline ECP & Emergency Contraceptive Pill \\
\hline FC & Female Condom \\
\hline FP & Family Planning \\
\hline FPC & First Point of Contact \\
\hline HIV & Human Immuno-deficiency Virus \\
\hline ICEC & International Consortium for Emergency Contraception \\
\hline IDP & Internally Displaced Person \\
\hline IUD & Intrauterine Contraceptive Device \\
\hline KAP & Knowledge, Attitudes and Practices \\
\hline LAC & Latin American Countries \\
\hline $\mathrm{MCH}$ & Maternal and Child Health \\
\hline MIS & Management Information System \\
\hline MISP & Minimum Initial Service Package \\
\hline MOHFW & Ministry of Health and Family Welfare \\
\hline NGO & Non-Governmental Organization \\
\hline $\mathrm{OCP}$ & Oral Contraceptive Pill \\
\hline PEP & Post-Exposure Prophylaxis \\
\hline PPAG & Planned Parenthood of Ghana \\
\hline PRC & Post-Rape Care \\
\hline RH & Reproductive Health \\
\hline RHRC & Reproductive Health Response in Conflict Consortium \\
\hline SDP & Service Delivery Point \\
\hline SGBV & Sexual and Gender Based Violence \\
\hline STI & Sexually Transmitted Infection \\
\hline SRH & Sexual and Reproductive Health \\
\hline TA & Technical Assistance \\
\hline UNFPA & United Nations Fund for Population Activities \\
\hline UNGA & United Nations General Assembly \\
\hline VCT & Voluntary Counseling and Testing \\
\hline WHO & World Health Organization \\
\hline
\end{tabular}





\section{What is emergency contraception?}

Emergency contraception (EC) is the term given to contraceptive methods that can be used by women in the first few days following unprotected intercourse to prevent an unplanned pregnancy (WHO 1998). EC should not be recommended or used as a regular contraceptive method. Emergency Contraceptive Pills (ECPs) contain higher doses of the hormones used in oral contraceptive pills. ECPs are effective in preventing pregnancy when taken within 120 hours (five days) of unprotected sex, although they are more effective the earlier they are taken. ECPs are sometimes inaccurately called "the morning after pill."

\section{Why are ECPs important?}

$\checkmark$ ECPs provide a unique opportunity for preventing pregnancy after unprotected sex that no other contraceptive method can provide.

$\checkmark$ ECPs can reduce the incidence of unintended pregnancy, which may otherwise result in an unsafe abortion.

$\checkmark$ ECPs are an important element in post-rape care as well as an essential component of reproductive health.

\section{When does a woman need to use ECPs?}

ECPs are used after unprotected sex. This can include the following situations:

$\checkmark$ when no contraceptive method has been used;

$\checkmark$ when a condom breaks;

$\checkmark$ when a woman forgets to take oral contraceptive pills for two or more days, or delays a scheduled injectable for more than two weeks; or

$\checkmark$ when a woman is raped/coerced into sex and is not currently using contraception.

\section{ECP options}

1. Dedicated progestin-only ECPs (specifically formulated and packaged ECP product): $1.5 \mathrm{mg}$ levonorgestrel taken in a single dose within 120 hours of unprotected intercourse, in either one or two pills. If a two-pill dose is used $(0.75 \mathrm{mg}$ each), these may be taken together or individually no more than 12 hours apart.

2. Combined regimen of progestin and estrogen (also known as the Yuzpe method): at least $100 \mathrm{mcg}$ of ethinyl estradiol and 500mcg of levonorgestrel taken as a first dose within 120 hours of unprotected intercourse, followed by a second dose 12 hours later. This regimen can be made by choosing appropriate birth control pills and calculating the number of pills needed for each dose.

3. Progestin-only oral contraceptive pills (OCPs): taken as a first dose of 20 pills within 120 hours of unprotected intercourse, followed by a second dose of 20 pills 12 hours later. This ECP option is not generally recommended due to the large number of pills required, but can be a back-up option in the absence of the other options.

A WHO multi-center randomized trial in ten developed and developing countries found a single $1.5 \mathrm{mg}$ dose of levonorgestrel to be as effective in reducing the risk of pregnancy as two $0.75 \mathrm{mg}$ doses taken 12 hours apart. Side effects did not differ between the regimens (von Hertzen et al. 2002). According to the International Consortium for Emergency Contraception (ICEC), "providers should advise women to take a single $1.5 \mathrm{mg}$ dose of the levonorgestrel-only ECP regimen" (ICEC 2003a). Option \#1 simplifies ECP use, but if not available, options \#2 and \#3 should be considered.

\section{Efficacy and side effects of ECPs}

The efficacy of ECPs in preventing pregnancy is lower than the efficacy of regular contraceptive methods. The figures below reflect the risk of pregnancy in the 72 hour period following unprotected intercourse.

Progestin-only:

$\checkmark$ Reduces the risk of pregnancy for that single act of intercourse by 60-90 percent (WHO et al 2005).

$\checkmark$ Side-effects: nausea in 23 percent of women and vomiting in 6 percent (WHO 1998). 


\section{Combined estrogen and progestin:}

$\checkmark$ Reduces the risk of pregnancy for that single act of intercourse by 75 percent.

$\checkmark$ Side-effects: nausea present in 43 percent of women and vomiting in 16 percent (ICEC 2004).

\section{Mechanism of action}

The precise mechanism of action of ECPs depends on the time in a women's menstrual cycle, when intercourse occurred, and when the ECPs are taken. ECPs cannot interrupt an established pregnancy or harm a developing embryo. According a joint statement issued by the ICEC and the International Federation of Gynecology and Obstetrics (FIGO), levonorgestrelonly contraceptive pills prevent pregnancy by either: 1) inhibiting or delaying an egg from being released from the ovary when taken before ovulation; or 2) possibly preventing the sperm and the egg from meeting by affecting the cervical mucus or the ability of sperm to bind to the egg.

Most studies show that levonorgestrel-only ECPs do not change the histological or biochemical characteristics of the endometrium, indicating that they have no mechanism to prevent implantation (ICEC and FIGO 2008).

"Emergency contraception is not the same as early medical abortion. EC is effective only in the first few days following intercourse before the ovum is released from the ovary and before the sperm fertilizes the ovum. Medical abortion is an option for women in the early stage of an established pregnancy, but requires a different drug from levonorgestrel" (ICEC and FIGO 2008).

Knowledge of how ECPs work is central to understanding the crucial difference between emergency contraception and early medical abortion. Confusion between the two has occasionally led to unjustified rejection or denouncement of ECPs. First, these are different compounds and categories of drugs. Secondly, ECPs are effective only in the first 120 hours after sexual intercourse - before implantation of the fertilized egg in the uterus begins, which is when pregnancy begins according to the medical definition. In contrast, medical abortion is the termination of early pregnancy through the dislodging of the implanted, fertilized egg.
ECPs should not be confused with misoprostol, mifepristone or RU486, which do have an abortive effect.

\section{Side effects}

The main side effects reported include:

$$
\begin{aligned}
& \text { Nausea and vomiting are the most } \\
& \text { common side effects. } \\
& \checkmark \text { Bleeding disturbances or spotting. } \\
& \checkmark \text { Other possible effects include headaches, } \\
& \text { dizziness, fatigue, and breast tenderness. }
\end{aligned}
$$

Most side effects generally disappear within 24 hours of taking the pills. To reduce the effects of nausea, ECPs can be taken with food, and anti-emetics can help women who have a history of nausea or vomiting when taking pills with hormonal content. If a woman vomits less than two hours after taking a dose of ECPs, the dose should be repeated. In cases of severe vomiting, EC can be administered vaginally (ICEC 2004).

\section{Repeat use}

There is no evidence that repeated use of ECPs is harmful for most women (Abuabara et al. 2004), apart from the enhanced risk of unintended pregnancy if ECPs are used routinely instead of a regular contraceptive method. ECPs are safe even when used more than once in a cycle (ICEC 2003b); however, repeated use of ECPs is not recommended for women who have sexual intercourse regularly or who may be exposed to STI/HIV infection. Other contraceptive methods are more effective at preventing pregnancy as well as more affordable, and condoms have the added benefit of protecting against STIs. If a client reports repeat use of ECPs, the health provider is advised to counsel her about switching to a regular contraceptive method.

\section{ECPs and STIs, including HIV}

ECPs do not protect against STIs, including HIV. If a woman has been raped, it is important to give her post-exposure prophylaxis (PEP) for STIs, within 72 hours of the incident. Routine prophylaxis for HIV is a matter of considerable controversy and is not a universally accepted standard of practice. Health workers should refer to local protocols dealing with HIV PEP if they exist (WHO 2003a).

\section{What to do after using ECPS}

Providers can use the opportunity of providing ECP to counsel clients on future safe sexual behaviors. They should recommend that clients: 
$\checkmark$ Use a barrier method or abstain from sexual intercourse until next menses.

$\checkmark$ Do not use ECPs as a regular contraceptive method.

$\checkmark$ Begin using a regular contraceptive method (see table below).

Providers can also counsel or refer clients for family planning or other reproductive health services, especially for rape survivors who need immediate medical management and psychosocial care (see section below).

\begin{tabular}{|l|l|}
\hline Method & When to start \\
\hline Condom & $\begin{array}{l}\text { Immediately after ECP use - condoms } \\
\text { provide dual protection against } \\
\text { pregnancy and HIV/STIs }\end{array}$ \\
\hline Oral & $\begin{array}{l}\text { The day after } 2 \text { nd dose of ECPs, or } \\
\text { within 1-7 days after menses }\end{array}$ \\
\hline Injectable & \\
\hline IUD & Within 1-7 days after menses \\
\hline Implant & \\
\hline
\end{tabular}

\section{The bridging role of ECPs}

\section{Bridging to regular contraceptive methods}

The moment when ECPs are provided presents an important opportunity to "bridge" clients onto a regular and more effective contraceptive method by communicating information about other available methods about the importance of dual protection (including male and female condoms) and about the correct and consistent use of contraception. A study in Bangladesh shows that, after initial use of ECPs (primarily because of method-use failure), the proportion of women using a regular method of contraception increased from 72 to 93 percent (Khan and Hossain 2008). In India, a follow-up of users six months after they had used ECPs for the first time showed that use of a regular family planning method increased significantly from 67 to 79 percent after using ECPs (Kumar et al. 2007).

\section{Bridging to other reproductive health services}

Provision and use of ECPs can also act as a platform for communicating a range of sexual and reproductive health messages and services to clients, including referrals for other reproductive health services. In Kenya for example, 62 percent of FP providers gave additional services to their EC clients even without a formal emphasis during training on "bridging." Most often, these included HIV/STI counseling or referrals for testing. Notably, nearly half of those counseled on FP accepted a new or different method, most often injectables or male condoms (Keesbury, Owino, and Bradford 2007). Provision of ECP can also reinforce HIV prevention efforts including serving as a critical back-up method for HIVpositive women or discordant couples in cases of method failure, and for those wishing to avoid the potential of mother-to-child transmission (Townsend et al. 2007).

\section{Provision of ECPs in different settings}

Emergency contraception is now available to women in over 140 countries around the globe, and over the counter in 44 countries (ICEC 2008). Depending on national laws, it can be provided through government, NGO and private clinics, private sector pharmacies and physicians, community health agents, and other types of service delivery points. Points of access vary, depending on the strength of public health systems and the penetration of the private market. In South Asia, for example, EC is provided primarily within well-established government family planning programs; in Africa, pharmacies tend to be the most common source of provision; and in Latin America and the Caribbean (LAC), it can be found both in public and private sector outlets.

However, there are very few developing countries in which ECP could be described as being an integral and readily available service within the national RH program. Those where it is readily available include Argentina, Brazil, Mexico, Peru, and Bangladesh. In several countries the method is more widely available, primarily through the commercial and NGO sectors rather than the public sector; however, for the majority of countries it is either not widely available or available primarily to meet the needs of women in specific situations, such as post-rape or university settings. This diversity raises the possibility of ECPs being associated with use by particular groups of women with specific needs only (in Ecuador the public sector provides ECPs only to rape survivors), and not as a method that may be of use to the general population following unprotected sex or method failure. In countries where there is substantial political or religious opposition to making ECPs more widely available, introducing it as a service for particularly vulnerable women, such as rape survivors, can serve as the basis for scaling up the service once introduced.

The primary goal of this handbook is to provide guidance on programmatic approaches to mainstreaming ECPs within a national $\mathrm{RH}$ 
program, so that it becomes as widely available as other contraceptive methods. ECPs are

frequently introduced into a country for specific groups of women with a higher unmet need than the general population. The following section will review the key lessons about programming ECP services for use by women with specific needs. These include young and unmarried women, survivors of sexual assault, and displaced women living in refugee camps.

Following this overview of programming for the needs of women in specific situations, the greater part of the handbook will review the key strategic steps that are critical for efforts to mainstream ECPs to increase their availability for the general public. Clearly, most countries may need to mainstream ECP provision to increase access for the general population while simultaneously implementing programs that can meet the needs of women in specific situations. The intention of producing this handbook is to provide guidance that can support RH policymakers and program managers to achieve both goals. 


\section{Identification of populations with specific needs}

Unintended pregnancy can place a burden on any woman, no matter what her situation. However, there are women in certain situations who are more vulnerable, both individually and socially, for whom EC can play an especially important role in maintaining their physical and psychological health by preventing an unintended pregnancy. In this section we review three of the populations whose needs may be better met by providing ECPs through specific delivery systems: survivors of rape, unmarried young women, and women living in refugee settings.

\section{Rape survivors}

Pregnancy resulting from rape is almost always unintended and traumatic. As a general principle, ECPs should be made available to all female survivors of rape who are of reproductive age or who show signs of secondary sexual characteristics, who are not pregnant, and who are not consistently using an effective form of contraception (WHO 2003a).

A pregnancy test is not required prior to providing EC after rape, but pregnancy can be ruled out by using a simple checklist (FHI 2007). In any case, providers should assure clients that even if the woman is pregnant, using ECPs will not harm the fetus. As EC must be administered within 120 hours of the rape and is most effective if used as early as possible, any education messages about post-rape services should emphasize the critical importance of obtaining ECPs (and in high HIV prevalence settings, HIV PEP also) as soon as possible after the rape (Keesbury, Skibiak and Zama 2006; Keesbury and Zama 2007; Vernon, Schiavon, and Llaguno 1997).

The narrow window of opportunity to reduce the risk of a pregnancy after rape requires that ECP information and services are provided at the first point of contact (FPC) with a rape survivor, or as soon as possible afterwards. The first point of contact varies considerably, but is usually either: (1) the place where the crime is first reported, most often at a police station, social services or public prosecutor offices, legal aid agencies or women's refuges; or (2) at the place where the survivor goes for treatment (either before or after reporting the crime), such as outpatient or emergency units at health facilities. Some countries have, or are developing, specialist centers that can provide all medical, legal, psychological, and other support for survivors at one point of contact (e.g. the Thuthuzela Rape Centers in South Africa [UNICEF 2008]).

In several countries (e.g. Ecuador, Guatemala, Mexico, and Zambia), ECP counseling and services have been introduced in police precincts and rape care centers. Experience shows that staff in these centers require more extensive training in counseling rape survivors than health staff and may require special approvals and support from the health sector. Having this service included in guidelines and protocols is essential for ensuring that the staff consistently deliver the services. When the ECPs themselves are not provided, these FPCs should refer survivors to pharmacies or clinics where they can obtain the pills and be provided written instructions on how to use them or, if available, to rape care centers where a broader set of needs can be cared for (Vernon, Schiavon, and Llaguno 1997; Taracena and Brambila 2001; Keesbury and Zama 2007).

Establishing ECP services for rape survivors at these FPCs may require training providers as community-based or employer-based contraceptive distributors under national guidelines. At a minimum, staff and managers should be trained on the following:

$$
\begin{aligned}
& \text { The characteristics of ECPs } \\
& \text { Identifying which rape survivors should } \\
& \text { be provided with ECPs }
\end{aligned}
$$

$\checkmark$ Counseling survivors about their options and providing ECPs or a referral for them

$\checkmark$ After provision, referring for STI/HIV PEP and medical and psychological trauma management (if not already received)
$\checkmark$ Depending on the individual's preference and the national legal framework, opening or a referral for opening a criminal case

Provision of ECPs at the FPC is strongly recommended over referring to another location because of the critical need for its immediate use, especially in situations that lack readily available transportation (Vernon, Schiavon, and Llaguno 1997; Vernon 1998; Kestler and Ramirez 2004; Keesbury and Zama 2007).

Female survivors of sexual violence often sustain physical injuries and after the assault are more likely than other women to have unintended pregnancies, report symptoms of reproductive tract infections, have multiple partners, and be less likely to use condoms 


\section{Providing ECPs at the first point of contact for rape survivors}

In Zambia, the majority (91\%) of rape survivors in the Copperbelt region go to the police before seeking healthcare (Keesbury and Zama 2007). Moreover, although 82 percent of all survivors managed to get to a health facility within the time window for ECPs, only 37 percent actually received ECPs from hospital staff. These results encouraged the Ministry of Health to train police officers as community-based ECP distributors. Estimates suggest that enabling police to provide ECPs could benefit up to 59 percent of rape survivors, with little difference between rural and urban locations (Keesbury, Skibiak, and Zama 2006).

However, the provision of ECPs at FPCs that do not have medically qualified staff may present certain challenges. In Bangladesh and India, although police stations are a common FPC, police refused to stock or provide ECPs and only reluctantly agreed to supply information about ECPs to survivors (Khan et al 2008).

Providing brochures on ECPs at the FPC rather than providing the method itself was used in Mexico because in the absence of official guidelines, staff at public agencies were afraid they could be charged with providing abortions and providing drugs without a medical license (Vernon, Schiavon and Llaguno 1998). Even when non-medical FPCs do commit to providing ECPs, compliance with service delivery might vary significantly, and constant monitoring and supervision of activities is required.

and other contraceptives (IFPP 2004). EC is only one component of a comprehensive post-rape care "package" of services necessary to reduce the range of possible consequences of sexual violence. As far as is possible, a comprehensive and integrated care package should be available, either in a single venue (e.g. the Thuthuzela model) or, more commonly, through a system of coordinated referrals among specialized units.

\section{Young women}

Young people are defined by WHO as those aged between 10 and 24 years, thereby including both adolescents (aged 10-19 years) and youth (aged 15-24 years). For most young people, this is a time of sexual initiation and experimentation, often characterized by infrequent, unplanned, and sometimes non-consensual encounters. By its very nature, this type of sexual activity is frequently unprotected or insufficiently protected against both pregnancy and STIs. Ensuring access to and use of ECPs can be a critical component in any RH program's efforts to reduce unintended pregnancies among this population. Young people may thus constitute an important and growing population to be reached with ECP services by a national $\mathrm{RH}$ program. Evidence from Kenya suggests that young people constitute as many as 80 percent of all public sector ECP clients, and 49 percent of those purchasing the method from pharmacies (Keesbury, Owino, and Bradford 2007).

Young people are not a homogeneous population, even within a particular country setting, and so ECP programming strategies to reach them need to be flexible. In most situations, ECP information and services should be made available through the same structures and programs as other youth reproductive health information and services, such as adolescent-friendly clinics, communitybased programs and, in some settings, schoolbased programs. Because many adolescents may feel shy, distrust established services, lack money, and have less knowledge than older people, it is even more important that ECP services for young people have the recommended characteristics of quality contraceptive services in general, including:

$$
\begin{aligned}
& \checkmark \text { Privacy and confidentiality } \\
& \checkmark \text { Easy accessibility } \\
& \checkmark \text { Reasonably priced services and supplies } \\
& \checkmark \text { Convenient and flexible schedules } \\
& \checkmark \text { Sensitive and approachable staff trained } \\
& \text { to counsel adolescents }
\end{aligned}
$$

ECP programming for adolescents through existing structures requires planning, budgeting, and undertaking activities that enable the inclusion of messages and informational materials within communications strategies, training of existing staff, and easy delivery and maintainance of commodity supplies. For example, within secondary schools, information about ECPs could be included within a broader curriculum covering sexual and reproductive health, or in special ECP-focused sessions that include this topic could be held for students, teachers, and parents. In tertiary, and some secondary education facilities, existing student health services can be equipped to provide ECPs, along with counseling and services for contraception and STI/HIV prevention. For further information on youth-friendly services 
see Youth Net/FHI (2004), and for resources to guide ECP programming for young people see Beitz et al. (2003) and Parker (2005).

Integrating ECP services with related youthfocused activities can also be an effective way to increase the range and impact of ECP messages, although a stand-alone project or program on ECPs for adolescents and youth may not be acceptable or feasible in many countries.

Further methods of reaching young people with information about ECPs include:
$\checkmark$ identifying and using media and information channels that are accessible to the youth population. For example, newspapers, hotlines, youth journals, websites and advertisements for events attended by youths.
$\checkmark$ making ECPs an over-the-counter (OTC) product available to young people. This would dramatically reduce medical barriers in accessing ECPs.
$\checkmark$ encouraging and training pharmacists to stock ECPs and to disseminate correct information to their clients, particularly youth.

\section{Women living in humanitarian settings}

Relatively little is known about how best to provide reproductive health services, including ECPs, in humanitarian settings. Service delivery to refugees and internally displaced persons (IDPs) tends to be adapted from models designed for stable communities, and there is little information about how these service delivery models are best used or adapted to the needs of refugees or IDPs. Moreover, the reproductive health status and needs of a refugee woman living long-term in a stable camp setting may be very different from those of refugees during the emergency phase of a crisis, or from IDPs and other war-affected groups (McGinn 2000). This section reviews some of the issues associated with programming ECPs in such settings.

Humanitarian emergencies may flare up in a short time period, and, by their very nature, may not allow time for intensive and comprehensive training of providers, which can include medical and paramedical staff as well as traditional birth attendants and trained field staff and volunteers. Ideally, providers should be trained and sensitized in advance, or, if necessary, by a dedicated RH advisor after the response begins (Goodyear and McGinn 1998). Medical staff should be trained to provide ECP counseling,

\section{Reaching young people with information about ECPs}

A study in Zambia found that pharmacists and peer educators were the most frequent sources of information on ECPs for adolescents, being more widely used than clinic-based providers and communitybased contraceptive distributors (Skibiak, Chambeshi-Moyo, and Ahmed 2001).

In Mexico, the IPPF affiliate MEXFAM introduced ECPs into the curricula of all reproductive health training courses for schools and communities and pioneered ECP services in adolescent-friendly clinics and in youth peer and community programs. Awareness of ECPs among youth significantly increased (Vernon and Durá 2004). Displaying posters, distributing postcards, and providing telephone hotlines have also proven effective in informing youth (Givaudan, Fuertes, and Vernon 1998; Vernon 1998; Ellertson et al. 2002).

In India, ECPs are now regularly advertised on many TV channels and FM radio stations popular among young people. The Ministry of Health and Family Welfare is establishing adolescent-friendly sexual and reproductive health clinics in rural health facilities and urban district hospitals; counseling on and provision of ECPs is one of the key components (MOHFW 2006).

In Kenya, the experience of training pharmacists in classroom settings was not satisfactory due to a high turnover of pharmacists and premature departures during training. The study concluded that onsite training and the provision of IEC materials would be more effective (Beitz et al. 2003). Another study in Kenya revealed that pharmacists do not engage their EC clients in broader discussions about their health, and therfore lose important opportunities to discuss STIs and other relevant $\mathrm{RH}$ issues (Keesbury et al.).

In Bolivia, training on-site pharmacy clerks to provide appropriate and adolescentfriendly information and services through role-playing with groups of adolescents substantially increased sales of ECPs (Arteaga and La Fuente 2001). 
STI screening, and prophylactic treatment to rape survivors, along with necessary trauma treatment.

Response programs may be required to be creative when sourcing providers of information and counseling. In the Kibondo camps of Tanzania, leaders elected by refugee women in the camps were trained to do community education and to counsel rape survivors. Traditional birth attendants and social services paraprofessionals were given violence-sensitivity training, which includes basic information on ECPs (Goodyear and McGinn 1998).

ECPs should be available right from the beginning of a response to a humanitarian crisis. WHO's Inter-Agency Working Group for Reproductive Health in Refugee Situations (WHO 2003b) has developed a Minimum Initial Service Package (MISP) to address the reproductive health needs of displaced women and girls, which includes ECP as one of the services to be provided. WHO has also included ECPs in the "New Emergency Health Kit," a package of basic commodities delivered immediately to every newly identified emergency site. Program staff working in emergency settings should be aware of the need to source, order, and distribute ECPs early in the emergency, tasks that may be neglected in the hectic first days.

The key barriers to providing ECPs in humanitarian settings are similar to those in the general population - women's (and health providers') lack of knowledge about ECPs, stigmatization of users, inadequate supplies, and provider insensitivity or bias. As in the general population, these barriers lead to underutilization. Data from refugee camps in seven countries show that 54 percent of female rape survivors did not receive ECPs within 120 hours of an incident in 2007 (UNHCR 2008). With this in mind, it is important to consider that to ensure compliance, one-dose dedicated ECPs may be more appropriate for transient clients.

Limited understanding and knowledge of ECPs in refugee camps often mirrors that of the pre-crisis population. A study in Kakuma camp in Kenya found that, as in the general population, ECPs were widely perceived to be abortifacients. Moreover, of the 34 percent of women and 27 percent of men who were aware of rape cases, only 11 percent knew that emergency contraception was available through the camp health services, demonstrating the need for greater information to be disseminated among refugee populations (Muia, Fikree, and Olenja 2000). After providing training on EC to professional service providers, women's support group leaders, community health leaders, community health workers, and family

\section{Health kits for emergency situations: procurement details}

UNFPA. 2001. The Reproductive Health Kit for Emergency Situations, 2nd Edition.

Order from: UNFPA Procurement Service Section, 220 East 42nd Street, New York, NY 10017, USA. Tel: +12122975398

Fax: +1 2122974916 .

World Health Organization. 1998. The New

Emergency Health Kit 98

Order from: IDA Foundation, P.O. Box 37098, 1030

$A B$ Amsterdam, The Netherlands.

Tel: +31204033051

Fax: +31204031854

Website: www.ida.nl/en-us/

World Health Organization. 2001. Clinical management of survivors of rape: A guide to the development of protocols in refugee and internally displaced persons situations. Available at: $h t t p / /$ : whqlibdoc.who.int/hq/2002/WHO_RHR_02.08.pdf

planning promoters in Kakuma, knowledge about the method more than doubled in the refugee population, from 15 to 35 percent (Muia et al. 2002).

A humanitarian response team may need to consider national laws and protocols in advance, and take timely steps to advocate for change, if appropriate. For example, NGOs in Sudan say that they do not advertise services for rape survivors because Sudanese law (Article 48) prevents doctors from treating rape survivors without a referral from the police department. Doctors and health personnel can be arrested for violating this law and some have been threatened, to prevent them from providing services. In Kakuma camp in Kenya, despite trained providers increased knowledge about EC among refugees, EC services could not be institutionalized and contraceptive services continued being provided as they had been before the training (Muia et al. 2002). 
Step 1.

\section{Registration of a dedicated ECP product}

In all countries, medical drugs and products need to be registered and to comply with national requirements before they can be made available to the population through public or private channels. The overall purpose of these regulatory requirements is to ensure the safety, efficacy, and quality of all medicines provided to the public. If a product is not registered (usually determined through a review of policy documents and/or interviews with key informants), then the process of registration explained below needs to be followed. If ECPs are already registered in the country, then proceed to Step 2, introduction of ECPs.

The process of product registration usually involves the following steps:

a. Identify partners to register the ECP product(s).

b. Conduct a pre-registration assessment, if appropriate.

c. Select partners and conduct advocacy with relevant authority.

\section{Identify partners to register the ECP product(s)}

The registration of pharmaceutical products can be a complex and lengthy process involving different steps and requirements. For this reason, in most countries reproductive health program managers have relied on product manufacturers and/or local distributors of pharmaceutical products to conduct the actual registration process and submit the required applications and documents. This also has the advantage that by involving the commercial sector, the distribution of ECP in pharmacies and other commercial outlets is achieved. Experience has shown that a local non-governmental partner is usually needed to undertake the registration process; the government agency in charge of medical product registration should be consulted for guidance in the procedures necessary for product registration in the country.

The most commonly required information for registering ECPs includes product information, manufacturing process, packaging requirements, clinical research results, product quality tests, and other product-specific information (PATH 2004). The active compound in ECPs is found in other contraceptives available in most countries and therefore governmental regulatory agencies

\section{Regimen advice}

It is important to ensure that, at the time of applying for registration, the latest available information on the drug is used. For example, WHO has currently approved one dose of ECP containing $1.5 \mathrm{mg}$ levonorgestrel. It is therefore advisable to register the $1.5 \mathrm{mg}$ levonorgestrel regimen first, as registering it after obtaining approval of the two-dose $0.75 \mathrm{mg}$ levonorgestrel regimen would require the whole process to be repeated.

can usually facilitate the registration of ECPs. Technical information on the product should be provided by the product's manufacturer in a confidential dossier that is submitted directly to the regulatory agency.

\section{Conduct a pre-registration assessment, if appropriate}

A test or assessment may or may not be a precondition of product registration. If it is required, it is necessary to determine:

$\checkmark$ the organization responsible for conducting the test (government institution or NGO).

$\checkmark$ the type of test (for example, a biomedical or field test).

$\checkmark$ who is responsible for utilizing the findings after the results are available.

\section{Field testing for registration}

In Ethiopia, the national Drug Administration Control Authority requires that new drugs be "field tested" prior to registration. For the $\mathrm{MOH}$ to introduce ECPs into their method mix, it was necessary to conduct in-country research. Instead of repeating the existing and universally-accepted clinical trials, the $\mathrm{MOH}$ undertook an operations research study. This effort demonstrated both the feasibility of providing ECPs in government facilities and its acceptability among clients. Combined with global clinical data, this evidence provided the basis for successful registration of the country's first-ever dedicated ECPs in 2006 (Keesbury, Aytenfisu, and Bradford 2007). 
Even if a pre-introduction assessment is not required by the government, the evidence provided by such an assessment can be used in subsequent advocacy campaigns to register and incorporate ECPs into the national reproductive health program, as well as help to counter the potential opposition posed by political and religious groups.

In some cases, the national $\mathrm{RH}$ program or an NGO can facilitate the registration process by conducting feasibility studies, market research, and/or "willingness to pay" surveys (which document the need, market, acceptability, and price of the product) and by raising the interest of manufacturers and distributors, including $\mathrm{RH}$ program and regulatory agency managers.

\section{Select partners and conduct advocacy with relevant authorities}

Changing policies and influencing programmatic decisions can better be achieved if a large number of agencies advocate for the change. If possible, partners with credibility such as RH service delivery organizations, feminist and legal aid organizations, $\mathrm{MOH}$ managers and donor organizations should be engaged in advocating for the introduction of ECPs with the relevant authority. Advocacy serves to sensitize political leadership, raise public awareness, and can potentially minimize the risk of community objections.

\section{Introducing ECPs through the Yuzpe regimen}

It is possible to introduce ECPs in countries without registered dedicated products by using the Yuzpe regimen, which involves provision of combined OCPs that are already registered for contraceptive use in most countries worldwide. In some Latin American countries, initial advocacy efforts included national and international seminars and workshops to present the Yuzpe method and generate buy-in from relevant actors, including policy makers and NGOs. As a consequence, the Yuzpe regimen was included in the official family planning service delivery guidelines in Brazil, and other countries, before dedicated products were available (Vernon 1998; Diaz et al. 2007).
Step 2.

\section{Introduction of ECPs into the public sector and $\mathrm{NGOS}$}

In most countries, the step of registering a product is conducted by pharmaceutical companies and distributors; therefore, the placement of ECPs in private sector pharmacies usually follows shortly after registration of the product. By contrast, the introduction of the product into large public sector and NGO service delivery organizations usually requires extensive advocacy and technical assistance. In most Latin American countries, and in Bangladesh, India, Nepal and Pakistan, for example, ECPs were registered and available in the private sector for several years before their introduction into public-sector programs. Experiences from several countries show that the process of introducing ECPs into public and/or NGO sectors varies significantly and so the following guidelines serve primarily to serve as a checklist of issues to consider when planning the introductory process. Moreover, government engagement and ownership of the process is essential for creating an enabling policy environment. Doing so often requires development partners to financially support the introductory process, broadening the base of national stakeholders and/or developing a formal national strategy that the government can endorse. The introductory step can include the following four activities:

$$
\begin{aligned}
& \text { Conduct a diagnostic assessment for the } \\
& \text { introduction/reintroduction of ECPs. } \\
& \text { Partner with stakeholders and } \\
& \text { conduct evidence-based advocacy with } \\
& \text { policymakers. } \\
& \text { If required, conduct operations research, } \\
& \text { feasibility and/or acceptability studies. } \\
& \text { Include ECPs in FP guidelines and other } \\
& \text { policy documents and plan for its phased } \\
& \text { introduction. }
\end{aligned}
$$
$\checkmark$ Include ECPs in FP guidelines and other policy documents and plan for its phased introduction.

\section{Conduct a diagnostic assessment for the introduction/reintroduction of ECPS}

Diagnostic assessments are a critical preintroduction stage and should include multisector consultations and dialogue to identify potential challenges and sources of resistance to ECP products and services. As a multi-party exercise, strategic assessments contribute towards generating knowledge, supporting consensus among country participants, and extending decision-making beyond the government. The assessment should include stakeholder and expert consultations, as well as qualitative and quantitative surveys to evaluate the perspective of decision makers, providers, 
and users. Sources of information for the assessment can include, among others, DHS surveys and other national and international research, policy documents, key informers in service delivery, policy, women's health advocacy, and legal aid organizations. The assessment should:

$\checkmark$ Help programs to understand the existing family planning policies and organization of services, to make recommendations on where ECPs could be offered, who could offer it, how to identify and train providers, which IEC materials would be needed, and how to include ECPs in commodity procurement and distribution processes, and within the management information system. The assessment should also determine if any policies would need to be updated, as well as the process for changing these policies, and how best to incorporate ECPs into the national FP service delivery guidelines.

$\checkmark$ Provide data to support the case for why ECPs would be useful within this population by describing current national levels of unprotected sex, proportions of unintended pregnancies, incidence of unsafe and safe abortions, incidence of rape, and method failure rates, among others.

$\checkmark$ Identify specific populations that could benefit from the introduction of ECPs and the feasibility of reaching these populations through various service delivery systems. As with most national RH programs, vulnerable sectors of the population, such as young women, the urban poor, and displaced and refugee populations, are harder to reach.

$\checkmark$ Collect information to help understand the cultural context and sensibilities around ECPs, which groups could potentially oppose its introduction as well as which reasons they may use and the types of messages that could be used to properly inform decision-makers.

$\checkmark$ Identify the most relevant stakeholders who could partner with programs in advocacy efforts and who should be provided information on ECPs. In several countries these have included not only reproductive health service delivery organizations, but also women's health organizations, members of the legislative and judicial powers, and the media.

\section{Using evidence to demonstrate ECP acceptability}

In Bangladesh, research demonstrated that 33 percent of pregnancies were unintended due to method failure or unprotected sex. Many of these pregnancies resulted in abortions performed in unsafe conditions leading to possible complications or death. Unprotected intercourse is common and frequent. These facts supported the introduction of ECP into the national program as a backup method for existing family planning methods (Khan and Hossain 2004).

In Ghana, the national IPPF affiliate facilitated the introduction of ECPs into the public sector by undertaking a pilot to demonstrate user acceptability of ECPs, training providers, initiating demand creation activities, supporting the registration of a dedicated product, and ensuring its availability by procuring and distributing it to providers in both the private and public sector (Osei 2007).

In Mexico, the introduction of ECPs into the public sector needed intensive advocacy efforts for almost a decade and required an external review of scientific evidence to prove that ECPs are not abortifacients. Support from feminist groups and other NGOs, as well as from individual MOH officials, were also factors that led to its introduction (Lara et al. 2007).

The Government of Nepal relied on IEC materials developed in Bangladesh and India and on technical assistance from the Population Council and a national research institution, the Nepal Fertility Care Centre, to introduce ECPs in a phased manner (Sherestha, Khan, and Hossain 2008).

In Pakistan, program managers were concerned about a possible backlash from conservative Muslims when introducing ECPs. Consequently, introduction of the method began only after a study tour by key stakeholders to Bangladesh, another country with a predominantly conservative Muslim population, to observe how it was provided and to gauge the population's response to its introduction (Khan et al. 2008a). 


\section{Partner with stakeholders and conduct evidence-based advocacy with policymakers}

NGOs and research institutions across the world have played an important role in encouraging governments to introduce ECPs into their reproductive health services. They have done this by providing policymakers with scientific information that presents a rationale for the introduction of EC and by sharing experiences of other programs. NGOs also typically play a critical role in ensuring EC supplies during introductory pilot projects, convening stakeholders, developing training curricula and providing training, facilitating guidelines on ECPs, and conducting diagnostic assessments. The likelihood of introducing and mainstreaming ECPs in the public sector is higher when done in partnership with organizations that have influence within government bodies, enjoy credibility for being honest, and maintain scientific rigor in their work. In the absence of substantial public sector involvement, ECPs may become the sole responsibility of NGOs or the private sector. As the former usually have limited coverage and the latter responds to market forces, this may mean that ECPs will not be available nationally and/or for those with specific needs, as is the case in Nigeria (Apsel 2007).

\section{If required, conduct operations research, feasibility and/or acceptability studies}

In several countries in Asia, Africa and LAC, diagnostic, social science, and operations research have been undertaken to provide policymakers with evidence regarding the feasibility and acceptability of ECPs. Without this evidence, it would not have been possible to revise existing policies, design an introductory strategy, or ensure that introduction of ECPs will not lead to controversies or backlash. When the results of feasibility studies, operations research, and program experiences from neighboring countries are convincing and credible, there may be no need to conduct additional studies.

\section{Include ECPs in FP guidelines and other policy documents and plan for its phased introduction}

The inclusion of ECPs into service delivery guidelines is an important aspect of the introduction process, especially if the method is to be mainstreamed. This process may involve a period of advocacy, technical assistance, and strategic planning by stakeholders and reproductive health experts. In some countries, such as Mexico, new contraceptives cannot be introduced into public sector programs until

\section{Using evidence to increase ECP availability}

In Bangladesh, policymakers questioned the social acceptability of the method and needed to understand the operational changes needed for introducing ECPs into the public health system. A formative study followed by operations research showed that women would use the ECPs if they were made available, that it was feasible to introduce ECPs into the government's program, and that paramedics as well as community workers could provide ECPs. These results facilitated the required policy change and the introduction of ECPs into the National Family Planning Program (Khan and Hossain 2004).

In India, ECPs were initially available only by medical prescription, which limited their use. The medical profession opposed making ECPs an over-the-counter (OTC) drug, which prevented paramedics from providing them. Policymakers requested research to show that paramedics and public extension workers could provide services of a similar quality to physicians. The study results supported this, and policymakers were willing to change national policy to make ECPs available over-the-counter (Kumar et al. 2007).

In Latin America, seven countries approved ECPs after $\mathrm{MOH}$ and $\mathrm{NGO}$ program managers attended a conference to review the results of operations research projects in other countries as well as other scientific evidence. They also received technical assistance to adapt the method in their service delivery guidelines and systems (Vernon 1998).

Despite nearly a decade of public sector provision, ECP use in Kenyan clinics and hospitals remained limited. To assist the $\mathrm{MOH}$ in meeting its dual goals of ensuring ECP access for adolescents and sexual assault survivors, the Population Council conducted a national assessment of public sector providers and facilities. It found that ECP services were biased toward sexual assault survivors and that the majority of providers were not sufficiently trained to offer ECPs in the context of family planning. In response, the MOH launched efforts to strengthen pre-service training on ECPs in medical and nursing schools, and to deliver contraceptive technology updates to in-service providers (Keesbury, Owino, and Bradford 2007). 
they have been included in the national service delivery guidelines, and the changes have been made official by publication in the official gazette. (In the private sector, however, standard drug registration regulations apply.) As has been the situation in Bangladesh and Kenya, if staff from the organization leading the introductory activities can work closely with the government (such as serving on its technical committees), opportunities arise for making changes to the guidelines and teaching curricula.

\section{Step 3.}

\section{Training and building the capacity of ECP providers}

Training service providers is a vital component for introducing and mainstreaming ECP services. In many contexts, particularly in larger countries, training can be costly and logistically challenging. The following section suggests various training strategies that can be adopted according to need and context, which will help to build the overall capacity of the RH system to organize and monitor training for introducing ECPs.

$\checkmark$ Who should be trained

$\checkmark$ What information a provider needs to know

$\checkmark$ Strategies for training service providers

$\checkmark$ Strategies for mainstreaming training in ECPs

\section{Who should be trained}

Providers of ECPs will differ in each country, depending on the whether they are being introduced through the public or private sectors, through clinics, pharmacies, outreach workers, or non-medical staff, as well as the regulations, cultural context, and preferences of key target

\section{Content of typical stand-alone training session}

First session: Overview of the demographic and reproductive health situation and discussion of the role of EC as a reproductive health intervention.

Second session: Definition of EC, and discussion of when and how ECPs should be taken.

Third session: Service delivery guidelines on how to provide ECPs, according to client's particular needs.

Fourth session: Counseling on ECPs, monitoring and logistics management, and frequently asked questions.

Example from Bangladesh (Khan and Hossain 2008)

populations. In both the public and private sectors, the following have been instrumental in providing EC information and services to women (PATH 2004):

$\checkmark$ Nursing and midwifery staff

$\checkmark$ Physicians

$\checkmark$ Paramedics

$\checkmark$ Trained community health workers

$\checkmark$ Adolescent peer educators

$\checkmark$ Private sector pharmacists and pharmacy counter staff

$\checkmark$ Gender-based violence (GBV)/rape survivor counselors and legal assistance

$\checkmark$ Police and forensic medical personnel

\section{Stand-alone training}

In Zambia, stand-alone training was used to provide police officers with the skills to deliver ECPs to sexual assault survivors. As non-medical personnel, their training required more time than health care providers. This training was conducted through a five-day course that followed a condensed version the MOH's curriculum for community/employer-based distributors. It focused on the essentials of reproductive physiology, contraceptive technologies, sexual assault response, integration with other services, and client/survivor counseling (Keesbury, Aytenfisu, and Bradford 2007).

In Bangladesh, stand-alone training was used when training the entire cadre of family planning providers (more than 45,000 providers). Senior program managers and district level officials were also oriented on ECPs before training of trainers and service providers. Initially, a group of master trainers was developed to train a large number of trainers, and the stand-alone training was then rolled out using a cascaded approach (see opposite page) (Khan and Hossain 2008). 


\section{What information a provider needs to know}

A training curriculum should include essential information about ECPs, an update of other contraceptive methods, related reproductive health issues such as STIs/HIV, and counseling on the importance of bridging to regular contraception and provision/referral for services (PATH 2004). Clinic and community health providers should also be trained to include ECPs in all FP counseling sessions and health education activities. The content, focus, and range of information communicated during the training will vary according to the type of provider. For instance, FP staff may require additional information on bridging to further FP and STI services, while pharmacists may benefit from advice on providing a confidential service. Capacity-building can start even before the registration of a dedicated ECP product, as combined OCPs are available in most countries and can be used for the Yuzpe regimen prior to the introduction of a dedicated ECP product.

\section{Strategies for training service providers}

$\checkmark$ Stand-alone/targeted training. Training specifically on ECPs is an effective means of building the capacity of specific groups of providers so that they have a comprehensive understanding of ECPs. This type of training can usually be done in a short period of time in a classroom setting for those providers who already have a basic understanding of and competency in providing FP services. Unfortunately, it can prove expensive, as it needs a distinct budget and may not be the best option for providers who cannot easily leave their place of work. This strategy may not be appropriate for scaling up the ECP program throughout a national public health system unless the required funds are available.

\section{Innovative training materials}

In Venezuela, ProSalud InterAmericana, a national NGO, has created an interactive CD that is distributed cost-free to service providers for their self-training on ECPs. The disc has been used by $\mathrm{NGOs}$ and $\mathrm{MOH}$ in several countries in the region (Martin 2004). For a demo of the CD, see http:// www.prosaludinteramericana.org/esp/cd/demo. html.

The Central Board of Health in Zambia, with NGO partners, developed a self-directed training manual on "Family Planning in Reproductive Health," which included a module on ECPs and counseling. Testing the approach demonstrated that it was as comprehensive as classroom training, although providers required 10-15 weeks to complete the course at their own pace (Keesbury 2007). $\checkmark$ Integrated training. Training on ECPs can be integrated with other training opportunities, such as contraceptive technology updates or other training on RH issues. This strategy can be more cost-effective than stand-alone training and can reach a large numbers of trainees, but it is important to ensure that the depth and quality of the training are not compromised. The major limiting factor is that it can only be used if other training opportunities exist that are timely and for the appropriate type of providers.

$\checkmark$ Self-directed training. Self-directed training is a tool that is used for distance education provided either completely or partly outside of a central facility. It requires supervisory support,

\section{Integrated training}

In India, the $\mathrm{MOH}$ adopted an integrated approach to train 200,000 health workers on ECPs because of the prohibitive cost of organizing stand-alone training. ECP training was integrated into the Reproductive and Child Health training program under which paramedics undergo three days of training. All paramedics were then reoriented in the new service, through a two-hour session on ECPs. Subsequently, ECPs have been included in the MOH Contraceptive Technology Update (CTU) manual.

The integrated training methodology has also been successfully adopted in Guatemala, El Salvador, and Kenya. In Kenya, ECP services were strengthened as a component of regular national CTU trainings provided by the Ministry of Health. This strategy ensured that ECPs were considered an essential component of routine family planning and reproductive health services and not as an additional burden on service providers. 
but may prove an effective option in circumstances where there are inadequate resources for stand-alone or integrated training, or where providers are unable to leave their work stations.

\section{Strategies for mainstreaming training in ECPs}

All three training strategies described above are suitable when introducing ECPs, and can be developed, tested, and revised through introductory pilot-testing. Once ECPs have been successfully introduced into the national program, which is usually on a small scale, a different training strategy is usually needed to mainstream ECPs throughout a national RH system. Three approaches can be recommended:

$\checkmark$ In-service cascaded training. Cascaded training can be a cost-effective means to reach large numbers of providers with in-service training. It can be used with either a stand-alone or integrated training curriculum, depending on whether there are funds available for supporting an ECP-specific training program (as was the case in Bangladesh, with funding provided by the Government, UNFPA, and USAID). There may also be regular training programs (for example, CTUs and the RCH program in India) into which ECP training can be integrated.

When designing a cascaded training strategy for a large-scale public program, it is advisable to develop a cadre of Master Trainers who can then train the trainers themselves. The Master Trainers and trainers are then available to build the capacity of service providers throughout the system. In Bangladesh, a total of 300 Master Trainers and 2,300 trainers were used to build the skills of 45,000 service providers (Khan and Hossain 2008). The cascaded training strategy is dependent on the funding available, the motivation and availability of all groups of trainers, and a consistent level of supervisory support to ensure that the training at all levels is of acceptable quality and occurs as planned.

\section{Steps for cascaded training in the public sector in Bangladesh}

$\checkmark$ Train a group of Master Trainers, who then...

$\checkmark$ Train a group of trainers, who then...

$\checkmark$ Train the service providers

\section{Integrating ECPs into pre-service training}

In Kenya, ECP advocates assisted in the review of the family planning curriculum of the National Medical Training College, providing the resources and technical expertise needed to strengthen instruction on ECPs. To support this new emphasis, the Population Council is providing a refresher course on EC for tutors nationwide.

In Bangladesh, a chapter on ECPs has been incorporated in the national contraceptive manual, which is the reference book for all paramedics and medical professionals working in the family planning sector.

Similarly, in India, ECPs have been incorporated in all MOHFW training manuals, such as contraceptive technology updates and a handbook for introducing adolescent-friendly clinics for reproductive and sexual health.

$\checkmark$ Pre-service training in EC by training institutions. The most cost-effective way to mainstream ECPs, certainly over the long-term, is to integrate them into pre-service training for personnel who will likely provide them as part of their work. The incorporation of ECPs into the curricula and training manuals of medical training institutions (such as medical schools, pharmacy schools, nursing schools, and paramedic training courses) is critical to institutionalize ECP training and secure its sustainability in the health system. This approach will also ensure that ECP training is provided to medical professionals working in both the public and private sectors.

$\checkmark$ Quality assurance and refresher training. Follow-up training is an important aspect of ongoing quality assurance. Refresher training, which can be done during routine supervisory, monitoring, and/or quality assurance visits by supervisors, should review and emphasize the key elements of delivering ECPs, as well as update providers on any recent developments and amendments to service delivery guidelines. Particular attention should be paid to ensure that providers are not letting personal biases prevent them from offering information and providing appropriate counseling, that they are emphasizing the need for bridging to 
regular contraception, and that they are screening for other RH needs, especially for STI/HIV management. For example, in Bangladesh, all supervisors have been instructed to ask questions about ECP services during visits and to conduct a 15-minute discussion during monthly staff meetings. Provision of ECPs is now included in the ministry's MIS system.

\section{Step 4.}

\section{Making the case for and raising public awareness of ECPS}

Raising public awareness about EC is a critical introductory step to ensure that the target populations, general and specific, are aware of the method, know how it works, and know where to obtain ECPs. Key messages and means of communication are described here for further detail and guidance (see box on opposite page).

Experience has shown that the following components will usually be necessary in any efforts to ensure that the potential users are fully aware of ECPs, that possible opponents can be educated on the benefits of ECPs, and that a case can be made for including ECPs in the national RH program.

$\checkmark$ Understand the social, cultural, religious, and legal context.

$\checkmark$ Select communication channels based on their audiences.

$\checkmark$ Use the media to reach specific audiences.

$\checkmark$ Develop the key messages.

\section{Understand the social, cultural, religious, and legal context}

The legal regulations in the country about where and how ECPs may be promoted need to be well understood. Many countries do not allow messages on contraception in the media or restrict the content and schedule of messages. For example, many Muslim countries prohibit advertising of family planning methods in general or of the condom in particular. It is also essential to understand the social, religious, cultural, and political environment of the country to avoid creating unnecessary controversies.

ECPs are relatively easier to introduce and mainstream in settings with higher levels of contraceptive knowledge and use. When a large proportion of couples are already protected by reliable contraceptive methods, however, the potential impact of a successfully introducing ECPs can seem marginal to decisionmakers. In

\section{Resources for outreach on ECPs}

Pathfinder:

$\checkmark$ Emergency Contraceptive Pills, 2nd edition. http://www.pathfind.org/site/DocServer/ ECP2ed_for_web.pdf?docID $=10203$

PATH:

$\checkmark$ Resources for emergency contraceptive pill programming: a toolkit www.path.org/files/RH_ec_toolkit.pdf

International Consortium for Emergency Contraception:

$\checkmark$ Adapting Resource Materials for Local Use. www.cecinfo.org/files/Adapting-materials.rtf

$\checkmark$ Materials for EC Advocacy - Questions and Answers for Decision Makers www.cecinfo.org/files/QA-for-Decision-Makers.rtf

$\checkmark$ Materials for EC Clients www.cecinfo.org/files/Sample-Mtrls-for-Clients.rtf

such cases, the rationale for introducing ECPs into a country should be framed in terms of meeting the needs of couples who experience method failure as well its role in post-rape care. In Bangladesh, where 60 percent of the population uses contraception, one-third of pregnancies are unintended and usually occur due to method failure. Similar arguments have worked well in Nepal and Pakistan.

Knowledge and awareness about ECPs among both providers and potential clients in all regions of the world is still quite low. Consequently, mass media campaigns to rapidly increase awareness and correct knowledge of ECPs at the population level can significantly and quickly increase the use of ECPs. The success of mass media campaigns, as seen in India, Kenya, and various countries of Latin America, was demonstrated in the sharp increase in ECPs sales in urban areas after advertising started. Short periods of widespread exposure to the correct information can be as effective as long-lasting media campaigns that target specific and/or geographically limited populations.

\section{Select communication channels based on their audiences}

The two primary audiences for mass media campaigns are potential users of ECPs and those who can advocate and provide information, counseling, and services. An assessment of the mass media available in the country, including their policies on the advertisement of contraceptive products and the types of audiences they reach, is essential before deciding to use this channel. 


\section{Strategies for engaging the mass media}

ECafrique has worked extensively with media partners to transform the public discourse on EC. In conjunction with a Kenyan media group, it prepared a "rapid response" kit to help journalists and NGOs respond to incorrect media reports and to inform articles supportive of EC and supported a four-day skills-building workshop for 22 leading health reporters from East and Southern Africa. The workshop led to over 50 stories on EC and other RH issues featured in print, radio, television, and the vernacular media (ECafrique 2006).

In Mexico, a press kit was sent to mass media organizations that covered health issues. Subsequently, more than 21 articles were published in national magazines and newspapers, six notes given on radio programs, and one mention in a national news program; ECPs were also included in the plot of a soap opera. It was estimated that this simple resource helped to reach 11.8 million persons, at a total cost of less than \$US 1,000 (Givaudan, Fuertes, and Vernon 1998).

Likewise, in India and Bangladesh the media played a positive role by publishing articles highlighting and supporting the need to introduce ECPs into the national reproductive health program. Extensive media coverage in India, which followed an advocacy project supported by the Packard Foundation, played a pivotal role in the subsequent approval of ECPs (Khan and Hossain 2008).

The press in Argentina covered the announcement of free government provision of ECPs and supported its introduction in university health services. Newspapers also denounced legal challenges, arguing that the new policy affected the most vulnerable who could not afford to buy ECPs from a pharmacy (La Nación 2007). The media have also been very actively involved in the public debate over public provision in Chile, adopting positions for, against, and neutral to EC (La Nación 2006; La Nación 2007; La Nación 2008; Faúndes et al. 2007).

It is possible to reach different audiences and communicate different messages depending on the media used (print, radio, television, or a combination). Such an assessment can be made by considering the following media outlets and opportunities available:

$\checkmark$ Newspapers, magazines, radio stations, and television channels publish information on contraceptive methods, reproductive health, gender, and women's empowerment. In Bangladesh, for example, journalists received information about ECPs and wrote articles during the pre-introduction period. In India, pharmaceutical companies used TV advertisements to make the public aware of ECPs.

$\checkmark$ Publicity and communications agencies can help to determine the channels, timing, frequency, and the duration of a planned campaign. They can also help develop and deliver the campaign messages. In some countries, such as Mexico, these firms have agreed to work on a pro-bono basis. In others, such as Kenya, Ghana and Ethiopia, social marketing firms have launched media campaigns intended to increase sales primarily in the private sector.

$\checkmark$ Producers and scriptwriters of soap operas and other entertainment programs could integrate EC into their storylines. In Mexico, a press kit on ECPs was sent to various media companies with suggestions on how to use the material based on examples from different countries. The script writers of one of the most popular soap operas at the time (Mirada de Mujer [A Woman's Glance]) introduced ECPs into the plot of the program, following the lead of a similar incorporation in $E R$, the popular medical series in the US.

$\checkmark$ Community-based channels - such as community radios, community theatres, and youth groups - could potentially include ECPs in ongoing activities.

$\checkmark$ Health and family planning telephone and internet hotlines can provide information on ECPs. In Kenya, counselors working at an $\mathrm{HIV} / \mathrm{RH}$ information hotline have been trained to answer questions on ECPs and provide referrals to other methods or services, such as VCT or post-rape care. In Bangladesh, pharmaceutical companies used hotlines to provide answers about their ECP products and how to use them.

$\checkmark$ Mass mailings: brochures, scientific articles, posters, and other printed materials can be sent to target audiences such as private physicians, pharmacists, women's health organizations, schools 
and universities, factories and assembly plants, and rape survivor care centers, among others. In Mexico, this strategy proved to be effective in increasing knowledge of ECPs among these groups. Further, it has been found that those who receive the IEC materials are likely to use them and to inform and train others (Givaudan, Fuertes, and Vernon 1997; Vernon and Llaguno 2001; Martin 2004).

\section{Use the media to reach specific audiences}

In Paraguay, through an alliance with PSI, the local IPPF affiliate Promesa conducted social marketing of Pronta ${ }^{\circledR}$, a dedicated progestinonly ECP product. At the beginning, extensive formative research was undertaken to develop the brand and marketing strategy; subsequent marketing efforts have primarily targeted service providers and youth. Promesa and PSI created an interactive CD of training materials for providers. Promesa also communicated with youth through a weekly radio program, a network of peer-educators/promoters, and other outreach facilitated by the internet and cell phone text messaging. Married women and men were also reached by integrating ECP messages in general, as well as information about Pronta ${ }^{\circledR}$ in particular, into Promesa's sexual health activities (Martin 2004).

In the absence of a commercial advertising campaign, marked increases in awareness can and have happened when national debates spontaneously generate mass media coverage, especially when such exposure is achieved through coordinated public communications strategies. This has happened in Argentina, Chile, Colombia, and Mexico (La Nación 2007; La Nación 2008).

In some countries, media coverage has been obtained through carefully planned public relations strategies, including several components such as press conferences, press releases, and widely distributed media kits. In other settings, media attention has been achieved through paid airtime by large-scale social or social-commercial marketing campaigns, as was the case of PSI's promotion of Postinor in Venezuela (ICEC 2005).

\section{Develop the key messages}

Different messages need to be considered for each of these audiences when raising awareness about ECPs. The emphasis of the messages will vary depending on the audience, but all messages should have correct, science-based information.

$\checkmark$ For potential users and providers. It is important that they know which ECP options are available, how and when ECPs can be used, dosage and schedule, sources of supply, mechanisms of action, possible side effects and management, and the need to bridge to a regular effective method.

$\checkmark$ For those who oppose ECPs. It is important to communicate ECPs' mode of action (i.e. that it is not an abortifacient), that its use does not lead to increased sexual activity or risky behaviors, and that it has a bridging role in encouraging regular use of more reliable contraceptive methods.

The following steps may help in the development of effective messages for both groups:

$\checkmark$ Identify existing IEC materials on ECPs that could be adapted and used in educational campaigns.

$\checkmark$ Pre-test the messages for clarity, cultural sensitivity, and appropriateness, and ensure that they appropriately address the information needs of potential users, providers, and opponents.

$\checkmark$ Give only one to three messages at a time.

\section{Reacting to negative media}

In Kenya and Botswana, media reports have suggested that increasing access to EC through pharmacies encourages adolescents to "eat ECPs like chocolates" (Okwemba and Anyona 2004). These reports, largely based on anecdotal evidence from a small number of pharmacists, have significantly threatened provision of ECPs in both countries. Reacting to these articles, policymakers became concerned that increasing availability of ECPs may encourage risky sexual behaviors in the context of high HIV prevalence. Advocates in both countries successfully lobbied against sustaining restrictions to access through personal communication and both governments are now working with ECafrique to develop strategies for ensuring responsible ECP provision in the private and public sector outlets. 
Step 5.

\section{Mainstreaming: Scale up and sustainable institutionalization of ECP services}

Introduction of ECPs into a national RH program is usually undertaken as a pilot project; once its provision is proven to be feasible, the challenges are (1) mainstreaming delivery of ECPs by taking to national scale those practices that were demonstrated to be feasible and effective during the pilot phase, and (2) ensuring that they can be sustained on a routine basis so that ECPs become a standardized method within the range of services made available. Anticipating and planning for scale-up and sustainability should be included at the outset of planning; if not, the activities proposed may not be replicable at a larger scale or sustainable over time. This is a critical issue and particularly relevant for the introduction of ECPs, given the sensitivities concerning the method, even after it has been proven socially acceptable and feasible to provide. In Zambia, for example, despite the success of pilot efforts and subsequent introduction into national FP guidelines, ECPs remain unavailable in the public sector due to limited funds for contraceptive procurement. Similar barriers have been seen in Ghana, Ethiopia, and Nigeria, where the achievements of introductory efforts flagged at the mainstreaming phase (Muteshi and Keesbury 2007).

There is no simple formula or framework for mainstreaming ECPs that could be described here, as each situation will determine how a successful pilot could best be scaled up. Key lessons drawn from a range of experiences with mainstreaming ECPs provide guidance on issues that should be considered, even before starting a pilot project.

\section{Scaling up the delivery of ECPs should} be one of the objectives when pilottesting its introduction. At the time of designing the introduction, the intention should always be that, whatever model is developed for delivering ECPs on a small scale, it should also be appropriate for delivering the method at a national scale. Regardless of whether mainstreaming will be in the public, NGO, and/or private sectors, this objective will influence decisions on:

$\checkmark$ choice of delivery system or program through which to provide the method.

$\checkmark$ design of the model for delivering ECPs (i.e. who, where, which product, what informational messages). $\checkmark$ funding for commodity procurement and delivery costs during and after the pilot phase.

2. The pilot intervention should address a felt need for the national program and have the potential to meet the needs of a substantially large population. For example, reducing unintended pregnancies and their adverse consequences is a priority for most health programs (including those due to method failure). In Bangladesh, about one-third of pregnancies every year are unplanned, and it is believed that most of these are terminated by unsafe abortion. Policymakers and program managers focused on the provision of methods to reduce the incidence of unplanned pregnancy. In Kenya, by contrast, policymakers were concerned about meeting the reproductive health needs of the country's large adolescent population. Based on research demonstrating that adolescents are the most frequent users of ECPs, the MOH decided to strengthen ECP provision to that target population (Morgan 2007).

3. Delivery of ECPs in the national program does not require major changes in the existing system. The prospect of having to make any major change in the existing FP delivery system will usually receive strong resistance from policymakers and program mangers, which reduces the likelihood of scaling up. Thus, ECPs should be introduced as one more option in the existing delivery system for contraceptives. For example, during introduction in Bangladesh, a onepage client registration form was supplied for providers to complete. After six months this form was dropped because of the additional work required of providers; they suggested adding a column to their existing client register instead, and this adjustment was used during nationwide scale-up.

4. Program managers responsible for scaling up ECP delivery should be involved in planning and implementing the pilot phase. It is easier to convince those who will have decisionmaking responsibility for planning and funding the mainstreaming of ECPs, should the pilot phase prove acceptable and feasible, if they are fully aware of and support the introductory model being piloted. If program managers do not have the time to get involved personally, they need to be briefed regularly and encouraged 
to contribute ideas or administrative support. In Ethiopia, turnover in the $\mathrm{MOH}$ has frustrated mainstreaming efforts, as original champions of ECPs were replaced by less supportive officials. This has stalled mainstreaming in the public sector, although product registration achieved under the pilot has enabled expansion of ECP services in the country's private sector.

5. Build strategic partnerships with organizations that can facilitate mainstreaming. Depending on the capabilities and resources of the organization(s) supporting the introductory and mainstreaming processes, partnerships with agencies that have specific technical expertise or credibility and/or donors with resources can be critical in successfully implementing both stages. In Bangladesh, with USAID funding, a group of organizations supported the Directorate General of Family Planning, including Population Council, JSI, and Pathfinder International. After its introduction, UNFPA became the main funding partner supporting the Government's scale-up program. In Kenya, the William and Flora Hewlett Foundation is supporting a national initiative to mainstream ECPs in the public and private sectors. Under this initiative, the Population Council has partnered with PSI, Marie Stopes/Kenya, the Pharmaceutical Society of Kenya, various commercial distributors of ECP products, and UNFPA.

6. Scale-up should be conducted in a phased manner. Once a pilot project has proven that ECPs and the model for their delivery are acceptable and feasible, it is not advisable to move immediately to national level scale-up. Scaling up on a gradual basis is recommended as the immediate phase after piloting, as this gives the opportunity to review, and adapt and modify if necessary the procedures and practices developed during the pilot phase. This first phase of the scale-up should be sufficiently large to learn about and fully understand the operational and management challenges of incorporating ECPs into the existing systems and to identify elements of the pilot model that are not replicable and should be left out (see diagram of the phased approach on the next page).

\section{Careful planning and monitoring for} procurement and logistical supply is essential. Logistical support is an important foundation for efficient ECP distribution, particularly during introduction and scaling up. The more common logistical problems experienced by large delivery systems may include: product registration and product procurement from manufacturers; poor distribution of ECP products or IEC supplies to service delivery points; or miscalculations of demand or procurement, leading either to stock-outs or over-stockages, resulting in expired products. In Bangladesh, for example, many facilities that received IEC materials did not distribute them to potential clients because experience with the public logistics system led them to believe that they would not get a re-supply on time. In Kenya, the MOH received a large consignment of ECP supplies prior to its integration into the logistics system and family planning registers; consequently, the supplies were not distributed systematically to provincial and district levels, often reaching facilities with no trained providers or procedures for resupply (Keesbury, Owino, and Bradford 2007).

8. Plan and budget for long-term technical assistance for the mainstreaming process, preferably using personnel from the pilot and/or limited scale-up phases. The introduction of any new service into a large delivery system requires some adjustments and capacity building to ensure its successful assimilation. Simply communicating the finding that ECPs are acceptable and describing the model by which it was introduced and delivered to program managers will not enable them to adapt it into their systems. Sustained technical assistance needs to be planned and budgeted, using those familiar with the ECP delivery model, until national mainstreaming has been achieved. Withdrawing technical assistance before the method is fully mainstreamed can lead to partial introduction and even discontinuation of its provision. This was the case in Ghana, where the Planned Parenthood Association of Ghana (PPAG) supported $\mathrm{MOH}$ efforts to introduce EC in the public sector through a series of pilot projects. The gains of this work, however, have not been widely replicated due to limited funding for PPAG's continued technical support and advocacy (Osei 2007). 


\section{A phased approach to introducing and scaling up ECP: The Bangladesh experience}

1. Diagnostic studies: Qualitative needs assessment for ECP services

2. OR to assess acceptability of ECPs and determine operational mechanisms for introducing ECPs

3. Recommend appropriate strategies to the $\mathrm{MOH}$ based on OR results

4. Presentation of OR results at the national level to the media, program managers, researchers, educationalists, and representatives of NGOs

5. Policy decision to introduce ECPs into the National FP program in two phases

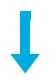

6. Phase I: Introduction of ECPs in Dhaka division covering a population of 45 million

7. Development of IEC and training materials

8. Training of 14,007 providers and provision of services

9. Monitoring of Phase I scale-up

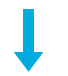

10. Phase II: Scaled up in the remaining divisions, covering a population of 89 million

11. Continue monitoring and gathering feedback from clients on service delivery

12. Necessary measures taken to improve service delivery and educate clients

9. Close monitoring of services at the initial stage of mainstreaming has crucial value. All components of a project or initiative to introduce ECPs into a national RH program (training, counseling, distribution, and communication) need systematic monitoring and documentation for two equally important reasons: 1) to ensure that the introductory activities were implemented as planned and are functioning efficiently; and 2) to have a record of the facilitating factors and obstacles encountered during the introductory process so that appropriate action can be taken when scaling up and mainstreaming these introductory experiences. Monitoring training and developing support systems can be used to provide feedback so that plans for training after mainstreaming is complete can be based on these experiences. Routine monitoring using MIS data can provide feedback once ECPs have been integrated into the family planning delivery system. These data can be used to identify service delivery points that need more training, supervision, or strengthening in general. Conducting rapid mid-term monitoring assessments (for example, after six months of service provision) can be useful to assess the quality of services provided-for example, whether new knowledge and skills have been retained.

\section{Monitoring and occasional evaluation} must be sustained once mainstreaming has been achieved. Three indicators can be used to determine when ECPs have been successfully mainstreamed in the system:

$\checkmark$ Inclusion of ECP products in the public health system's essential commodities list so that there is a regular line item in the contraceptive procurement budget.

$\checkmark$ Inclusion of ECPs in the national contraceptive MIS system, which shows a commitment to monitor the performance of the program in terms of its capacity to deliver ECPs.

$\checkmark$ Documenting the number and proportion of providers and facilities reporting that stock and distribute or sell ECPs as one of their standard services or products.

Monitoring should continue after the delivery of ECPs has been fully assimilated into public health, private, or NGO delivery systems. At this point the focus of monitoring shifts from documenting implementation of introductory activities to routinely measuring the delivery of ECPs as one FP service within the overall RH program. Special periodic surveys can provide important data on program performance-for example, through inclusion of questions or modules on ECPs in national and district-wide reproductive health surveys. In Kenya, such a survey was undertaken after nearly a decade of ECP service provision, allowing program managers to reflect on the success of their efforts and reorient strategies where necessary (Keesbury, Owino, and Bradford 2007). Furthermore, data on the bridging role of ECPs to increase regular use of FP will support recognition of ECP introduction and mainstreaming as an important reproductive health intervention. 
Abuabara, K. et al. 2004. "As often as needed: Appropriate use of emergency contraceptive pills," Contraception 69(4):339-342.

Apsel, D. 2007. "Emergency Contraception in Nigeria. A Case Study," unpublished paper.

Arteaga, Elizabeth and Ivonne La Fuente. 2001. "Las Farmacias como Principales Proveedores de Orientación y Provisión de Métodos Anticonceptivos a Adolescentes" [Pharmacies as the main providers of counseling and contraceptive methods for adolescents], FRONTIERS Report. La Paz, Bolivia and Washington D.C: Population Council.

Bacic, M., A. Wesselius de Casparis, and E. Diczfalusy. 1970. "Failure of large doses of ethinyl estradiol to interfere with early embryonic development in the human species," American Journal of Obstetrics and Gynecology 107(4):531534.

Beitz, J et al. 2003. "Youth-Friendly Pharmacy Program Implementation Kit: Guidelines and tools for implementing a youth-friendly reproductive health pharmacy program." Seattle: PATH.

Díaz, J. et al. 2007. "Scaling up family planning service innovations in Brazil: The influence of politics and decentralization," in Scaling Up Health Service Delivery: From Pilot Innovations to Policies and Programs, Simmons R., P. Fajans, and L. Ghiron (eds.). Geneva: WHO Press, pp. 135-155.

ECafrique. 2006. Working with the Media to Increase Public Awareness on Emergency Contraception: A Case Study. Nairobi: ECafrique.

Ellertson, Charlotte et al. 2002. "Information campaign and advocacy efforts to promote access to emergency contraception in Mexico," Contraception 66(5):331-337.

Family Health International (FHI). 2007. "How to be reasonably sure a client is not pregnant," a checklist. Research Triangle Park, North Carolina: FHI.

Faundes, A. et al. 2007. "Emergency contraception under attack in Latin America: Response of the medical establishment and civil society," Reproductive Health Matters 15(29):130-138.

Fernandez, C. Araceli and Ricardo Vernon. 2007. "Introduction and expansion of emergency contraception: Lessons from Latin America and the Caribbean for a global guidance tool," unpublished paper.
Fernández, A. et al. 2008. "Introduction and scaleup of emergency contraception products and services: Lessons learned from the field in three continents," unpublished paper.

Givaudan, M., C. Fuertes, and R. Vernon. 1998. "Testing strategies to disseminate knowledge of emergency contraception," INOPAL III Final Report. IMIFAP and Population Council: Mexico and Washington, DC.

Glasier, A. et al. 2004. “Advanced provision of emergency contraception does not reduce abortion rates," Contraception 69(5):361-366.

Goodyear, L. and T. McGinn. 1998. "Emergency contraception among refugees and the displaced," Journal of American Medical Women's Association 53(5 Suppl 2):266-70.

Hatcher, Robert A. et al. 1997. The Essentials of Contraceptive Technology. Baltimore:

Johns Hopkins Bloomberg School of Public Health, Population Information Program.

International Consortium for Emergency Contraception (ICEC). 2003a. "Regimen Update." $<w w w . c e c i n f o . o r g>$ . 2003b. "Repeated Use of Emergency Contraception: The Facts." <www.cecinfo.org $>$

ICEC. 2004. "Emergency Contraceptive Pills: Medical and Service Delivery Guidelines." $<w w w$. cecinfo.org>

ICEC. 2005. The Emergency Contraception Newsletter. Winter 2004/2005, Vol. 9, No. 2.

ICEC. 2008. "ECP Status and Activity by Country." $<w w w . c e c i n f o . o r g>$

ICEC. "Adapting Resource Materials for Local Use." <www.cecinfo.org $>$

ICEC. "Materials for EC Advocacy: Questions and Answers for Decision Makers." <www.cecinfo.org>

ICEC. "Materials for EC Clients."

$<w w w . c e c i n f o . o r g>$

ICEC and the International Federation of Gynecology and Obstetrics (FIGO). 2008. "How do levonorgestrel-only emergency contraceptive pills prevent pregnancy?" $<w w w . c e c i n f o . o r g>$ 
International Family Planning Perspectives. 2004. Editorial, International Family Planning Perspectives 30(4).

International Planned Parenthood Federation/ Western Hemisphere Region (IPPF/WHR). 2006. Every Woman's Right: Recommendations for Improving Knowledge and Access to Emergency Contraception. New York: IPPF/WHR.

Keesbury, J., J. Skibiak, and M. Zama. 2006. "Reducing unwanted pregnancy among victims of sexual assault: New windows of opportunity for emergency contraception," unpublished paper.

Keesbury, J., B. Owino, and S. Bradford. 2007. "Emergency contraception, female condoms and IUDs in Kenya's public sector: Findings from a national diagnostic assessment." Nairobi: Population Council.

Keesbury, Jill, Hailegiorgis Aytenfisu, and Spike Bradford. 2007. "Mainstreaming emergency contraception in Ethiopia's public sector." Nairobi: ECAfrique, Population Council, and Ethiopian Society of Obstetricians and Gynecologists.

Keesbury, Jill. 2007. "From pilots to regional programs: Expanding contraceptive choice and improving quality of care in Zambia's Copperbelt: Final project report." Nairobi: Population Council.

Keesbury, Jill and M. Zama. 2007. "Emergency contraception for survivors of sexual assault: New windows of opportunity in Zambia," a presentation at the Global Health Conference, Washington, DC, 29 May - 1 June.

Keesbury, J. et al. "Who uses EC in Kenya? An analysis of ECP pharmacy clients," unpublished paper.

Kestler, Edgar and Lilian Ramirez. 2004. Informing the medical community in Guatemala about emergency contraception," FRONTIERS Final Report. Washington, DC: Population Council.

Khan, M.E. and S. Hossain. 2007. "Introducing, promoting, and scaling up emergency contraception in South and Southeast Asia: Regional synthesis paper," unpublished paper.

Khan, M.E. and S.M.I. Hossain. Forthcoming. "Introducing emergency contraceptive pill in the national FP program of Bangladesh: Enhancing utilization of OR results and lessons learned from program implementation," FRONTIERS Final Report. Washington, DC: Population Council.
Khan, M.E. et al. 2008a. "A situation analysis of care and support for rape survivors at first point of contact in India and Bangladesh," FRONTIERS Final Report. Washington, DC: Population Council.

. 2008b. "Introduction of emergency contraceptive pills in the public health system of Pakistan: A south-to-south collaboration," FRONTIERS Final Report. Washington, DC: Population Council.

Khan, M. E and SMI Hossain. 2004. "Introducing emergency contraceptive pills in Bangladesh: A feasibility study," FRONTIERS Final Report. Washington, DC: Population Council.

Kumar et al. 2007. "Provision of emergency contraception services through paraprofessionals in India," FRONTIERS Final Report. Washington, DC: Population Council.

LaNación.cl. 2008. "Al calor de las sábanas municipales [Under city sponsorship],” in LaNacion.cl., 25 May 2008. Santiago. <http://www. lanacion.cl/prontus_noticias_v2/site/edic/2008_ 05_25_1/port-domingo/fk_portada.html>

LaNación.cl. 2007. “Otro debate sobre la píldora del día después. En Ushuaia evitan su distribución [Another debate about the morningafter pill: Avoiding distribution in Ushuaia]," in La Nacion.cl., 3 May 2007. Buenos Aires. <http:// $w w w \cdot$ lanacion.com.ar/nota.asp?nota_id=905334>

La Nación. 2006. "Polémica discusión: La píldora del día después, gratuita. La extenderán por ley a todo el país [Controversy: The morning-after pill, free: Available country-wide by law]," in $L a$ Nación, 16 November 2006. Buenos Aires. <http:// www.lanacion.com.ar/nota.asp?nota_id=859258>

Lara, D. et al. 2007. "Introducing emergency contraception in the Mexican family planning official norm," Gaceta Médica de México 143(6):483-487.

Martin, A. 2004. "Emergency contraception in Latin America and the Caribbean," Revisita PanAmerican de Salad Publica 16(6):424-431.

McGinn, Therese. 2000. "Reproductive health of war-affected populations: What do we know?" International Family Planning Perspectives, 26(4): 174-180.

Ministry of Health and Family Welfare (MOHFW). 2006. Implementation Guide on Reproductive and Child Health II. Adolescent Reproductive Sexual Health Strategy: Handbook for State and District Program Mangers. New Delhi: MOHFW. 
Morgan, G. 2007. "A profile of EC Users in Kenya," a presentation delivered to a national EC strategy development workshop, Nairobi, Kenya, 28 August 2007.

Muia, Esther, Fariyal F. Fikree, and Joyce Olenja. 2002. "Enhancing the use of emergency contraception in a refugee setting: Findings from a baseline survey in Kakuma refugee camps, Kenya.” Nairobi: Population Council.

Muia, E. et al. 2002. "Evaluation of an emergency contraception introduction project in Kenya," Contraception 66(4):255-260.

Muteshi, J. and J. Keesbury. 2007. "Regional synthesis paper: Emergency contraception: Lessons from Africa," unpublished paper.

Okwemba, A. and J. Anyona. "Having fun with morning-after pills," Daily Nation. 13 May 2004: 25-26.

Osei, I. F. 2007. "Emergency contraception in Ghana: A case study," unpublished paper.

Parker, Chris. 2005. "Adolescents and emergency contraceptive pills in developing countries," FHI Working Paper Series No. WP05-01. Research Triangle Park, North Carolina: FHI.

PATH. 2004. Resources for Emergency Contraceptive Pill Programming: A Toolkit. Seattle: PATH.

Pathfinder. 2007. Emergency Contraceptive Pills, 2nd edition. Watertown, MA: Pathfinder International.

Planned Parenthood Federation of America (PPFA). 1998. Emergency Contraception Handbook. New York: PPFA.

Population Council. 2006. "Facts about emergency contraceptive pills," fact sheet. New York: Population Council.

Population Services International (PSI). 2007. "Products and Services." <www.psi.org/our_ programs/products/ec.html>. Accessed January 2008.

Raymond, E.G., J. Trussell, and C. Polis. 2007. "Population effect of increased access to emergency contraceptive pills: a systematic review," Obstetrics and Gynecology 109(1):181-88.

Schiavon, R. 2006. “Adolescentes y Anticoncepción de Emergencia” [Adolescents and emergency contraception]. Gaceta Médica de мéxico. 142:6.
Sebastian, Mary P. et al. 2005. "Studying the utilization of emergency contraceptive services through paramedics in India," FRONTIERS Asia and the Near East Region Research Update no. 5. New Delhi: FRONTIERS/Population Council.

Skibiak, John P., Mangala Chambeshi-Moyo, and Yusuf Ahmed. 2001. "Testing alternative channels for providing emergency contraception to young women.” Nairobi: Population Council.

Sherestha, Mohindra, M. E. Khan, and Sharif Mohammed Ismail Hossain. 2008. "Strengthening emergency contraception in Nepal," FRONTIERS Final Report. Washington, DC: Population Council.

Taracena, Berta and Carlos Brambila. 2001. "Reproductive health promotion for women victims of violence and rape." Guatemala City: Population Council.

Townsend J. et al. 2007. "EC bridging in Africa: ECAfrique," a presentation at the International Consortium on Emergency Contraception, New York, 4 October.

United Nations Population Fund. (UNFPA). 2001. The Reproductive Health Kit for Emergency Situations, 2nd edition. Geneva: UNFPA.

United Nations Children's Fund. (UNICEF). 2008. "Thuthuzela Care Centres." <www.unicef.org/ southafrica/hiv_aids_998.html>. Accessed March 2008.

UN High Commissioner for Refugees (UNHCR). 2003. "Sexual and Gender-Based Violence against Refugees, Returnees and Internally Displaced Persons: Guidelines for Prevention and Response."<http://www.rhrc.org/pdf/gl_sgbv03_ 00.pdf $>$. Accessed March 2008.

Van Hertzen, H. et al. 2002. "Low dose mifepristone and two regimens of levonorgestrel for emergency contraception: a WHO multicentre randomised trial," Lancet 360(9348):1803-10.

Vernon, Ricardo, Rafaella Schiavon, and Silvia Elena Llaguno. 1997. "Emergency contraception as an element in the care of rape victims," INOPAL Final Report. Washington, DC: Population Council.

Vernon, Ricardo. 1998. "Experiences in the diffusion of emergency contraception in Latin America," in Reproductive Health Operations Research 1995-1998. Washington, DC: Population Council.

Vernon, Ricardo and Maricela Durá. 2004. "Improving the reproductive health of youth in Mexico," FRONTIERS Final Report. Washington, DC: Population Council. 
Vernon, Ricardo. 1999. "Mexico: Informing service providers and factory workers about emergency contraception," FRONTIERS Final Report.

Washington, DC: Population Council.

World Health Organization (WHO). 1998. New Emergency Health Kit 98. Geneva: WHO.

WHO and UNHCR. 2001. Clinical Management of Survivors of Rape: A Guide to the Development of Protocols in Refugee and Internally Displaced Persons Situations. WHO and UNHCR.

WHO, UNDP, UNFPA, and World Bank. 2005. "Levonorgestrel for emergency contraception," fact Sheet. Geneva: WHO, Special Program of Research, Development and Research Training in Human Reproduction.

World Health Organization, Department of Reproductive Health and Research (WHO/RHR) and Johns Hopkins Bloomberg School of Public Health/Center for Communication Programs (CCP) INFO Project. 2007. Family Planning: A Global Handbook for Providers. Baltimore and Geneva: CCP and WHO.

WHO. 2005. "Emergency Contraception," fact sheet no. 244. Geneva: WHO.

WHO. 2003a. Guidelines for medico-legal care for victims of sexual violence. Geneva: WHO.

. 2003b. "Minimum Initial Service

Package (MISP),” fact sheet. Geneva: WHO.

Youth Net/FHI. 2004. Youth Friendly Services: An Annotated Web-based Guide to Available Resources. Arlington, Virginia: FHI. 